\title{
AVALIAÇÃO DE USABILIDADE DA INTERFACE COMPUTACIONAL DE ENTERPRISE RESOURCE PLANNING
} (ERP)

\author{
Ronei Baúl ${ }^{*}$, Jean Carlos Hennrichs ${ }^{2 * *}$ \\ ${ }^{1}$ Graduado, Universidade do Oeste de Santa Catarina - UNOESC, 89.813-000,Chapecó, Brasil. \\ 2 Professor, Universidade do Oeste de Santa Catarina - UNOESC, 89.813-000,Chapecó, Brasil. \\ *E-mail: ronei.bau@gmail.com \\ **E-mail: jean.hennrichs@unoesc.edu.br
}

\section{RESUMO}

Este estudo busca apresentar algumas técnicas e ferramentas de IHC (Interface Homem- Computador) que auxiliam na identificação de problemas de usabilidade e possíveis soluções para estas inconsistências, em um sistema de ERP (Enterprise Resource Planning) já existente e em uso comercialmente. A pesquisa de campo constou da aplicação da técnica de Card Sorting, em clientes reais da empresa Uninfo Sistemas de Chapecó-SC, para avaliar a taxonomia da interface principal do ERP Softcom Slim. A partir dos resultados coletados criou-se um protótipo estático com a nova taxonomia proposta, e por fim, a avaliação desta nova taxonomia por meio do tempo de execução, número de cliques no mouse e traçado percorrido. A escolha da realização da pesquisa em um sistema já em uso comercialmente mostrou vantagens e desvantagens. A maior vantagem identificada foi o conhecimento prévio do usuário ao sistema, pois tal conhecimento auxilia na identificação de pontos falhos da taxonomia do sistema avaliado. Em contrapartida, a maior desvantagem foi à baixa aceitação de participação dos clientes que usam o software em questão, neste caso sendo o fator tempo como motivo principal da falta de disponibilidade do usuário em participar da pesquisa. Concluída a pesquisa e o estudo proposto chegou-se à conclusão que a taxonomia da interface do software ERP Softcom Slim necessitaria de alguns ajustes para tornar o mesmo mais ágil, eficiente e eficaz.

Palavras-chave: Interface Homem-Computador. Card Sorting. Usabilidade de interface. Tempo ideal via KLM.

\section{Introdução}

A interface de um aplicativo computacional é a parte visível do software, é o canal pelo qual o usuário efetua interações com o software. Desta forma possui grande importância o seu estudo, pois é através da opinião do usuário que se pode medir a qualidade do produto, conforme justifica a NBR-ISO/IEC 9126-1 [1], que define qualidade em uso como sendo a qualidade do produto de software do ponto de vista do usuário.

Considerando que muitas vezes um programa durante sua criação é levado em conta muito mais o seu funcionamento do que como que ele será utilizado, não é dispensada a devida atenção para a interface, desta forma, questões como a facilidade de uso do programa ou se o usuário gosta de utilizar o programa acabam por surgir como questões inquietantes. Em contraponto a esta problemática, a NBR ISO/IEC 12207 [2] nos traz a importância da interface estar presente nos requisitos de elaboração de um programa. Assim também a importância da usabilidade, esta definida pela NBR-9241-11 [3] como uma medida que pode ser utilizada pelos usuários a fim de realizarem seus objetivos de um modo eficiente, eficaz e satisfatório.
Sendo assim este artigo teve como objetivo uma pesquisa de campo para avaliar a interface computacional do programa Softcom Slim da empresa Uninfo Sistemas de Chapecó-SC, levando em consideração aspectos relacionados ao seu uso. Para tal atividade utilizou-se de técnicas como Card Sorting e Wireframe a fim de identificar um padrão de taxonomia de menus e de interface que propicie, do ponto de vista do usuário maior qualidade de uso do sistema.

\section{Fundamentação teórica de pesquisa}

A fundamentação teórica deste trabalho abordou assuntos como: IHC; Psicologia cognitiva; Cardsorting; Wireframe; Experiência do Usuário; Avaliação de usabilidade de interfaces e; Tempo ideal de realização de uma tarefa.

\subsection{Conceitos de interface homem-computador}

Antigamente apesar de sua importância, as interfaces eram simples, devido à baixa capacidade computacional levando em consideração aos dias de hoje. Isso se explica pelo fato de que 
somente um pequeno grupo de pessoas fazia uso dela, pois eram poucos os que usavam computadores.

Com o surgimento de novos grupos de usuários, a interface torna-se mais evidente e passa a ter maior importância. Inevitável que com essa diversidade de usuários ocorra insatisfação por parte de alguns quanto ao uso da interface, tornando culpado todo o sistema. Segundo Pressman (2010) [4] em algum momento todo o usuário já vivenciou uma experiência com interface aonde a mesma lhe pareça estranha, confusa, ilegível ou frustrante.

Tomando por base a interface, é nela que é empregada toda a expectativa do uso deste software, acabando esta se tornando o cartão de visita do programa e é por esse motivo que ela deve ser de fácil uso, que transponha clareza e objetividade, que seja agradável ao usuário. Cybis (2007) [5] expõem sobre a dificuldade da criação de interfaces que sejam ergonômicas devido às mesmas serem criadas para sistemas onde todo o tipo de usuário estará interagindo e por esse usuário carregar consigo uma bagagem única, ele coloca que dificilmente dois usuários distintos interpretarão uma interface da mesma forma.

Nota-se aqui que além da interface, outra parte que deve ser dada grande atenção é com relação ao usuário, desta forma conhecer o usuário é fator indispensável para a criação de uma boa interface.

\subsection{Psicologia cognitiva e modelos mentais}

A psicologia cognitiva estuda a cognição, o ato de se adquirir conhecimento, ou seja, estuda os processos mentais que são gerados a cada comportamento realizado no ato de aprender.

Segundo Cybis (2007) [5], o conhecimento das características humanas como percepção, raciocínio e memória, levando-se em conta capacidades e limitações destas áreas, o planejamento e controle de atividades mentais inclusive emocionais, é muito importante para a construção de uma interface eficaz e eficiente em um sistema interativo.

O ser humano forma modelos mentais para associar algo a alguma coisa ou função em seu processo de aprendizagem. Cybis (2007) [5] informa sobre a importância de se descrever os menus condizentes com os títulos das janelas que aparecem para o usuário. O modelo mental criado no processo de aprendizado pelo usuário será de fácil acesso a memória quando solicitado a lembrar sobre determinada tela ou função.

Reduzir a carga de memória do usuário é um método utilizado para facilitar a interação entre o usuário e sistema. Pressman (2010) [4] expõe que muito mais propenso a erro será a interação, entre o usuário e o sistema, se o usuário tiver uma carga de lembrança grande para efetuar uma tarefa. Alguns pontos que podem auxiliar neste processo de redução de carga de memória são: definir atalhos que sejam intuitivos; layouts de telas que representem tarefas do mundo real; revelar informações de um modo progressivo; entre outros.
A importância de conhecer o usuário para desenvolver um sistema com qualidade fica clara e é justificada pela NBRISO/IEC 9126-1 [1] que demostra, entre os requisitos da qualidade, que a qualidade do software é visualizada no seu uso, e que se baseia no ponto de vista que o usuário tem em relação a esse uso do software.

Existem diversas técnicas para se conseguir gerar e organizar as ideias dos usuários, dentre elas pode-se destacar: Brainstorming (Tempestade de Ideias); Diagramas de Afinidades; Card Sorting (Arranjo de Cartas), entre outros.

\subsection{Card Sorting - Taxonomia aplicada}

Dentro das técnicas de concepção de interface Cybis (2007) [5] destaca a técnica chamada de Card Sorting também conhecida por "arranjo de cartas". Encontra-se nessa técnica uma maneira de propiciar a organização das funções que são apresentadas na interface. Esta técnica também proporciona grande troca de informações entre usuários e desenvolvedores, possibilitando assim programar uma interface que seja organizada de forma a prover uma redução de carga de memória do usuário e fazer com que o mesmo possa utilizar a interface de maneira ágil e agradável dentro da taxonomia escolhida.

A técnica consiste na organização de fichas (cartas) contendo informações, desta forma o analista entrega uma quantidade de cartas ao usuário onde o mesmo deve organizar as informações contidas nos cartões de formas associativas entre eles.

Cybis (2007) [5] expõem sobre a importância de o analista deixar claro para o usuário que ao final da aplicação da técnica podem "sobrar" fichas que não tenham associação a nenhum grupo pela concepção do usuário, porém, deve-se sempre pedir para o usuário se esforçar para utilizar todas as fichas nos grupos. Faria (2010) [6] coloca que a técnica de Card Sorting é um método de alto poder de análise de usabilidade, é um método rápido, barato e seguro que serve se entrada de informação para o processo de estruturação de um sistema.

A aplicação desta técnica pode ser utilizada no processo de elaboração de um novo produto ou na reestruturação de um produto existente, auxiliando na (re)organização e categorização das funções, ou seja, proporcionando uma taxonomia entre as funções expostas na interface.

Faria (2010) [6] ainda menciona que a técnica sozinha não é capaz de definir uma estrutura final, pois sempre pode haver discordâncias entre o entendimento das funções existentes na interface ou por desentendimentos entre usuários quanto aos agrupamentos.

Esta técnica, porém, serve somente para categorizar funções da interface, não expressa como, por exemplo, o posicionamento destas categorias na interface. A estrutura da interface pode ser elaborada de modo rápido por softwares que implementam técnicas de prototipagem rápida como o Wireframe. 


\subsection{Wireframe}

O Wireframe é uma técnica geralmente utilizada na elaboração de web sites, mas pode ser utilizada em diversos outros produtos a fim de criar uma visão semi detalhada sobre o que se pretende desenvolver.

Quando Cybis (2007) [5] menciona sobre técnicas de concepção de software expondo a técnica de protótipos em papel, de forma alusiva esta sendo a mais próxima em semelhança com a técnica de Wireframe. O autor explica que esta técnica propicia uma troca de experiência entre usuários e desenvolvedores, pois estes últimos podem descobrir sobre preferências e limitações dos usuários, estes que por sua vez acabam aprendendo mais sobre as propostas no sistema a ser utilizado.

Brown (2007) [7] define Wireframe como sendo ilustrações de forma bruta que demonstram com um maior ou menor grau de detalhes o conteúdo das telas. Essas ilustrações são chamadas de Wireframe devido não serem designs elaborados, são de linhas simples, mas que demonstram que tipos de informações serão apresentadas.

Conforme Reis (2007) [8] o Wireframe apresenta uma disposição dos elementos a serem visualizados pelo usuário, uma sugestão espacial de como será o layout da interface, apesar dele considerar que este não é o foco da técnica, pois pode restringir a liberdade do design gráfico.

Em contra partida a este último autor, pode-se encontrar situações em que o método de Wireframe pode muito bem ser utilizado para categorizar e ordenar as informações e ao mesmo tempo dar liberdade de expressão para o design gráfico.

AMSTEL (2005) [9] nos mostra um bom exemplo disso quando expõe a situação de que Wireframe deve ser o mais simples possível, até porque quando apresentado para o cliente, a fim do mesmo aprovar ou não, qualquer modificação a ser realizada fica fácil de ser efetuada, já que não houve perda de tempo para elaboração do esboço primário, ficando fácil à alteração já que não é nada muito elaborado.

\subsection{A experiência do usuário}

Considerar a experiência que o usuário final possui com relação a ambientes computacionais é de suma importância para auxiliar na elaboração de uma interface que agrade ao usuário.

Segundo Nielsen (1993) [10] ele coloca três dimensões com relação à experiência do usuário: uma visão de experiência quanto ao sistema; quanto a computadores e; quanto ao domínio da tarefa a ser executada.

$\mathrm{O}$ autor demonstra que o usuário encontra-se sempre entre novato ou experiente, seja da visão quanto ao computador quanto ao sistema ou quanto ao domínio de uma tarefa.

Percebe-se que quanto maior é a experiência, seja em qualquer uma das perspectivas, maior é a tolerância do usuário com relação a atitudes inesperadas. Desta forma a experiência do usuário pode proporcionar uma maior usabilidade do produto ou serviço utilizado.

Uma interface bem projetada também inclui a parte estética da interface, Cybis (2007) [5] coloca o exemplo de pesquisas relacionadas ao uso dos terminais de caixas automáticos, onde a pesquisa constituía em comparar o layout de diversos desses terminais. Os layouts eram idênticos com relação ao número de funções e botões e forma de utilização, a única diferença era na aparência das telas e botões. Esta pesquisa foi realizada por pesquisadores japoneses e israelenses em momentos diferentes, e em ambas o resultado foi que os usuários achavam mais fácil, mais agradável e aprendiam melhor com as interfaces esteticamente melhor elaboradas.

Assim como a ergonomia é importante para o usuário, o prazer em utilizar um produto também tem sua importância. Tamanha é essa importância que (Cybis, 2007) [5] apud (Hancock et al., 2005) define que esse prazer encontrado na interação entre homem e tecnologia é chamado de Hedonomia.

\subsection{Avaliação de usabilidade de interfaces}

A avaliação de interface tem como um dos objetivos, o de entender o que o usuário realmente quer. Baranauskas \& Rocha (2000) [11] coloca que quanto mais informações o designer tiver do usuário, melhor será a interface que o mesmo irá criar.

Uma avaliação de usabilidade pode incluir um ou mais métodos ou técnicas de avaliação, ou seja, de se conseguir informações referentes à interface.

Baranauskas \& Rocha (2000) [11] divide em dois grupos o processo de avalição de interface:

1 - Inspeção de usabilidade: Este método não recebe influência dos usuários e pode ser implementado em qualquer etapa do desenvolvimento de um sistema;

2 - Testes de usabilidade: Já este método é totalmente centrado no uso do sistema pelo usuário, para a aplicação deste método é necessário que exista alguma forma em que o sistema seja apresentado ao usuário, seja por simulações, protótipos ou pelo uso efetivo do próprio sistema já em produção.

$\mathrm{O}$ autor ainda coloca que os testes realizados com usuários, ou seja, testes de usabilidade é um método fundamental para se aplicar e conseguir informações pertinentes ao uso do sistema e ao usuário que o utiliza.

Nielsen (1993) [10] norteia sobre as métricas para medir a usabilidade, onde define a taxa de sucesso como a principal métrica por ser simples de direta. Coloca ainda que essa taxa pode ser desdobrada baseada na taxa de erros que o usuário comete ao realizar uma tarefa, ou seja, se o usuário realizou uma tarefa, mas durante o percurso cometeu erros, a mesma pode ser considerada como um sucesso parcial.

Cita ainda Nielsen (1993) [10], que outra métrica bastante comum, de modo quantitativo e que pode inclusive ser utilizada como auxiliar da taxa de sucesso de uso de um sistema, é a de tempo de execução de uma tarefa, onde, por exemplo, pode-se 
contabilizar o tempo que é levado para que o usuário realize uma determinada tarefa, e após compara-se este tempo com o tempo ideal de realização desta mesma tarefa.

\subsection{Estimando tempo ideal de uma tarefa - KLM}

Para estimar o tempo de execução de uma tarefa, Kieras (1993) [12], em seu artigo coloca como utilizar o modelo Keystroke-Level Model - KLM proposto pelos autores Card, Moran, \& Newell em 1983.

O modelo basicamente consiste em listar, em um determinado cenário todos os passos, ou seja, ações que o usuário precisará realizar em sequência para efetuar uma tarefa, logo após, basta somar o tempo decorrido de todas as ações.

Tais ações são os níveis de keystroke. Por exemplo: mover o mouse a um determinado ponto; clicar em um botão; pressionar uma ou uma sequência de teclas; entre outros. Desta forma as ações ficam mais específicas e melhor de serem detalhadas do que uma operação descrita como, por exemplo, registro no sistema, que se torna muito abstrato, pois não é uma operação única, tendo em vista que para realizar o registro no sistema depende de uma sequência de operações.

Segundo o autor existem certos operadores básicos para o uso no modelo KLM em que seus tempos de execução já foram devidamente estimados em experimentos. Desta forma utilizando os operadores do modelo KLM para atribuir os tempos de cada operação, pode-se estimar o tempo ideal para a realização de qualquer tarefa a ser avaliada no sistema.

\subsection{Outliers}

A definição de Outliers dada por D. Hawkins encontrada no documento de Prati (2013) [13] é a de que este é um fato que se desvia tanto dos outros a ponto de gerar suspeitas de que este fato tenha sido gerado por algum outro mecanismo que não seja o comum a todos os demais.

Um Outlier sugere um desvio de padrão, e por isso pode ser amplamente utilizada, como exemplo na identificação de fraudes ou na detecção de intrusões, pois ataques a sistemas computacionais apresentam comportamento diferente do seu modo normal de uso.

Porém, tal desvio pode causar grande impacto no resultado final se o Outlier for analisado juntamente com todos os fatos ou dados de uma pesquisa, devido isso, é muito importante saber identificar um Outlier.

\section{Metodologia}

O trabalho de avaliação de interface consistiu em realizar uma pesquisa de campo que teve como início janeiro de 2013 até novembro de 2013. Dentre as técnicas empregadas, foram utilizadas entrevistas, observação dos usuários, aplicação de testes em telas e em algumas funcionalidades do sistema ERP Softcom Slim, além de aplicação de questionário aos participantes determinados na amostragem e utilização de técnicas como Card Sorting e Wireframe para identificação de padrões de taxonomia e de layouts de telas.

A realização desta pesquisa foi de caráter exploratório, descritiva e explicativa tendo em consideração os meios empregados na realização desta pesquisa.

Com relação às características quanto aos meios empregados na realização da pesquisa, pode-se definir que devido aos fins determinados, a mesma foi uma pesquisa de campo, utilizando-se também do caráter bibliográfico e experimental.

A população da amostra foi determinada pelo cálculo matemático $\mathrm{x} * 80 / 100$, onde $\mathrm{x}$ corresponde à quantidade de clientes existentes na cidade de Chapecó, que se enquadrem no perfil da pesquisa definido e disponibilizados pela empresa Uninfo Sistemas e 80 / 100 para que seja possível captar até $80 \%$ dos clientes disponibilizados. Este cálculo resultou em uma população de 40 clientes, destes, para se ter confiabilidade de 95\% seria necessário entrevistar 36 clientes.

Ao final da pesquisa obteve-se o seguinte cenário conforme demonstrado na (Tabela 1).

Tabela 1 - Amostragem detalhada.

\begin{tabular}{cc}
\hline Ações & Quantidade \\
\hline Entrevistas válidas & 11 \\
Não mais clientes & 3 \\
Entrevista Incompleta & 7 \\
Recusa total & 15 \\
\hline Total & $\mathbf{3 6}$ \\
\hline
\end{tabular}

Foram considerados como entrevistas válidas os clientes que executaram todos os passos da pesquisa, sendo estas as entrevistas a qual baseia-se toda a análise dos dados. Quanto ao fator entrevistas incompletas, foi considerado os clientes que mesmo após toda a explicação e exemplificação da pesquisa e após a mesma ter dado seu início, se recusaram a efetuar algum procedimento da pesquisa. Sobre o fator recusa total, foram considerados clientes os quais não se dispuseram a participar da pesquisa.

\section{Resultados e discussões}

$\mathrm{Na}$ esfera pesquisada identificou-se, nas entrevistas válidas, que: $73 \%$ dos entrevistados eram do sexo feminino; $37 \%$ encontra-se com idade entre 30 a 34 anos; 55\% alegaram ter uma experiência moderada quanto ao uso de computadores e navegação na web; $55 \%$ utilizam o software Softcom Slim a cerca de 4 anos e; $36 \%$ fazem uso do software por mais de 10 anos. Este último resultado identificado evidencia a grande 
experiência dos usuários quanto ao uso do sistema, dando maior confiabilidade na presente pesquisa.

Quanto à utilização do sistema foi possível identificar um equilíbrio entre os usuários onde $45 \%$ das entrevistas válidas consideram não ser nem difícil nem fácil usar o sistema e 55\% consideram ser de fácil utilização.

Com relação à navegabilidade do sistema, $73 \%$ das pesquisas válidas consideram o sistema ser de fácil navegação, sendo que este mesmo percentual considera também ser fácil identificar a localização das funções dentro do sistema.

Referente ao grau de dificuldade do usuário quanto ao entendimento dos termos e expressões utilizadas no sistema, verificou-se que $64 \%$ dos voluntários, considerados válidos, consideraram ser de fácil entendimento, porém somente $45 \%$ ressaltaram que utilizar os menus é fácil. Os outros $55 \%$ relataram não ser nem fácil nem dificil a utilização dos menus do sistema.

Foi questionado aos usuários quanto à memorização de funções do sistema pelos seus ícones que a representam, com a intenção de verificar se tal opção deve continuar para novas versões da interface. Este fator se mostrou muito positivo, pois obteve aceitação de $73 \%$ do público pesquisado válido.

Dos usuários entrevistados, $73 \%$ informaram ter conhecimento de que o sistema proporciona algum meio de solução de dúvidas imediatas, e dentre as soluções que os usuários consideram ser mais eficaz na solução de dúvidas, 55\% acreditam que janelas com dicas sobre o campo em dúvida seria o ideal, sendo este um item inovador para o sistema, pois poderá auxiliar os usuários na utilização do sistema.

A fim de verificar junto aos entrevistados uma solução para que o mesmo pudesse localizar alguma função do sistema em menor tempo, foi questionado se estes gostariam que o sistema proporciona-se algum campo de pesquisa. Desta forma obtive-se o resultado de aceite de $91 \%$ dos usuários pesquisados. Esta opção também não se encontra na versão atual do sistema, o que poderia contribuir em muito na satisfação do usuário para com o sistema avaliado.

Ao questionar os usuários pesquisados quanto ao layout de menus que estes gostariam de utilizar, 73\% optaram pela opção a qual se assemelha ao layout atual, demonstrando que os usuários já estão acostumados ao modelo empregado e uma quebra de paradigma neste ponto poderia vir a criar certa dificuldade em uso.

Com os dados coletados da pesquisa foi possível identificar que os usuários pesquisados, em maioria, consideram de forma razoável a utilização dos menus e do sistema Softcom, porém, consideram ser fácil o uso quanto a navegação, identificação de localização de funções dentro do sistema e interpretação dos termos e expressões utilizados. Alegaram ainda conhecer a existência de teclas de atalho, contudo as utilizam esporadicamente.

\subsection{Definição do percurso ideal e número de cliques}

Além dos dados coletados na pesquisa anteriormente, foi contabilizada a taxa de sucesso de uso do sistema Softcom Slim. Para tal foi utilizada a métrica de avaliação do tempo ideal para a realização de uma tarefa, métrica esta proposta por Nielsen (1993) [10].

Para a mensuração do tempo ideal para a realização de uma tarefa, se fez uso da técnica de definição do percurso ideal. O percurso percorrido por cada participante da pesquisa foi capturado por meio da gravação, em background, da realização da tarefa.

A técnica de definição do percurso inicial consistiu inicialmente da definição de qual seria a posição inicial do mouse. Nesta pesquisa foi determinado o centro da tela do como ponto inicial. Ponto este devidamente identificado no momento do início da gravação, por um ícone próprio do software de captura de vídeo que indica sempre o local central da gravação. Como a gravação, em background, foi em tela cheia, o centro da tela foi o ponto inicial do traçado.

A fim de identificar o menor caminho a percorrer com o mouse para a realização da tarefa, levando em consideração a utilização somente de menus e guias de acessos a janelas, desconsiderando qualquer atalho do sistema, foi traçado uma linha reta até o ponto central de cada opção que permita acesso ao passo seguinte. Neste ponto central de cada opção a ser selecionada, foi identificado a opção de acesso com a numeração de identificação de cliques. Desta forma foi possível chegar a definição de traçado e número de cliques ideal para a realização da tarefa proposta.

A Figura 1 representa a tela do computador com o percurso ideal a ser percorrido para a conclusão efetiva da tarefa.

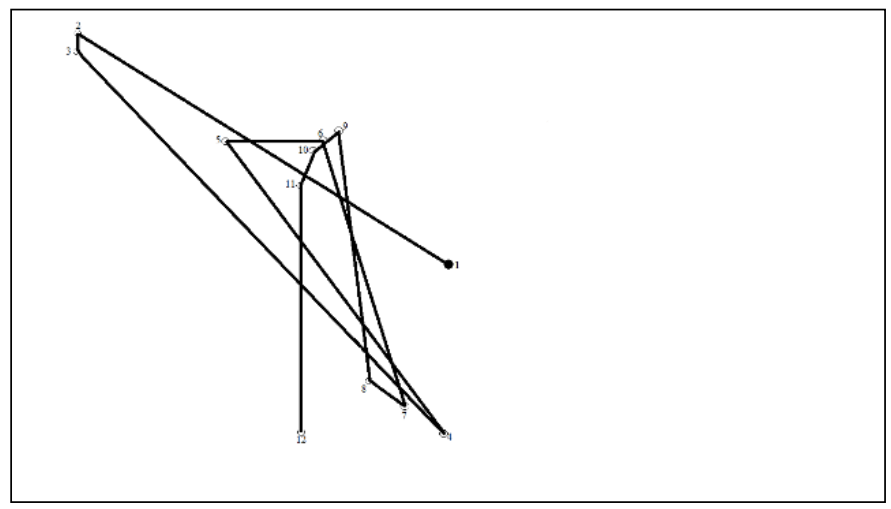

Figura 1 - Traçado e número de cliques ideal.

\subsection{Definição do tempo ideal}

Para determinar o tempo ideal para a realização da tarefa foi utilizado o modelo KLM utilizando os valores padrões e medianos propostos pelo método e identificados no artigo de 
Kieras (1993) [12], tendo assim seus pesos apresentados na Tabela 2.

Tabela 2- Tempo ideal da tarefa.

\begin{tabular}{cccc}
\hline Operador & Valor & $\begin{array}{c}\text { Tempo KLM } \\
\text { (segundos) }\end{array}$ & $\begin{array}{c}\text { Tempo Ideal } \\
\text { (segundos) }\end{array}$ \\
\hline K & 10 & 0,28 & 2,8 \\
P & 11 & 1,1 & 12,1 \\
B & 11 & 0,1 & 1,1 \\
H & 2 & 0,4 & 0,8 \\
M & 11 & 1,2 & 13,2 \\
W & 8 & $1,0 \quad$ Total & 8,0 \\
\hline & & \multicolumn{2}{c}{} \\
\hline
\end{tabular}

Desta forma identificou-se que o tempo ideal para a realização da tarefa proposta pela pesquisa é de 38 segundos com um número total de 11 cliques.

De posse de tais informações foi possível efetuar uma análise comparativa com os resultados obtidos dos entrevistados que será mais bem evidenciado no subcapítulo seguinte.

\subsection{Estatística de execução da tarefa}

Com o tempo, traçado e número de cliques ideal para a realização da tarefa, passou-se para a fase de análise dos dados coletados junto aos participantes da pesquisa.

Para a identificação do tempo e número de cliques efetuado por cada usuário pesquisado, fez-se uso da análise da gravação da capturada durante a realização da tarefa. Porém para a captura do traçado ideal foi utilizado o software MouseHeatMap, executado em background, que capturou as áreas quentes da interface durante a tarefa proposta.

Com as imagens das áreas quentes de cada participante do estudo, foi possível efetuar uma sobreposição de imagens entre o traçado ideal e o percorrido pelo usuário, como pode ser verificado na Figura 2, que evidencia a captura das áreas quentes de quatro usuários distintos realizando a mesma tarefa.

Efetuando essas sobreposições de imagens entre o traçado ideal e o traçado percorrido pelos 11 usuários, juntamente com o compilado das informações de tempo, número de cliques e êxito ou não da tarefa registrados pelo software de captura da tarefa do usuário em vídeo, chegou-se ao resultado de que apenas $18 \%$ dos entrevistados concluíram a tarefa com total êxito, enquanto que
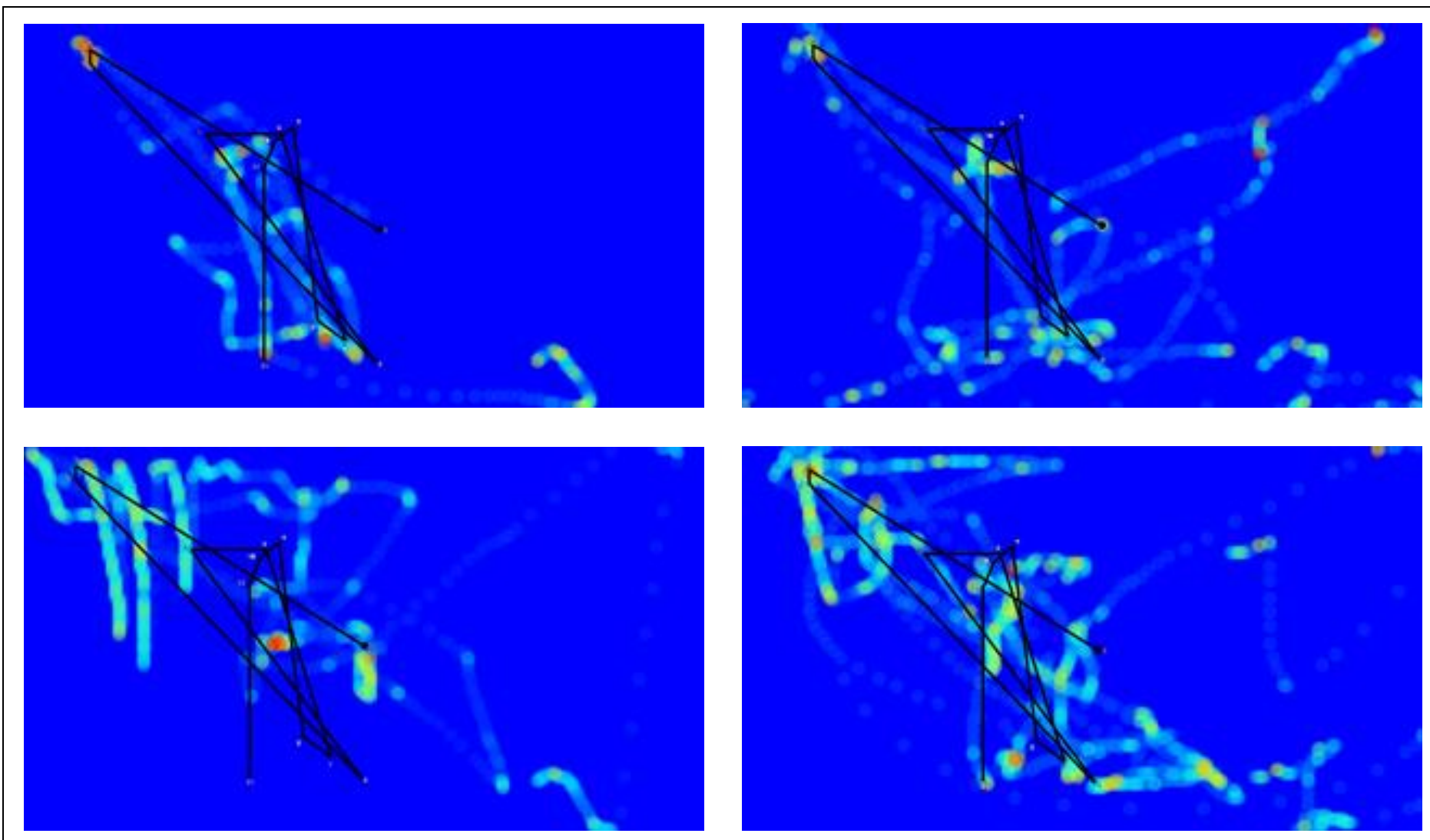

Figura 2 - Captura das áreas quentes de quatro participantes Versus o Traçado ideal 
$55 \%$ concluíram a tarefa com sucesso parcial, ou seja, no decorrer da tarefa cometeram erros. Pela análise do elevado tempo decorrido, número de cliques e áreas percorridas fora do traçado ideal, por esses participantes, presume-se que estes não tinham um conhecimento prévio de como se localizar no sistema para a execução da tarefa parcial ou completamente, conseguindo a execução da mesma por tentativa e erro. Os $27 \%$ restantes dos entrevistados, não conseguiram finalizar a tarefa, desistindo da execução da mesma por não conseguirem cumprir com o que fora proposto.

\subsection{Análise websorting}

Para a análise dos dados obtidos pelo método de Card Sorting foi utilizado um framework web disponível em http://websort.net/manager/. A webapp cita e efetua o cruzamento das informações a fim de auxiliar na descoberta de um melhor agrupamento de informações para encontrar a taxonomia ideal dos menus do sistema que foi avaliado.
Neste framework foram registradas todas as 77 opções existentes na tela principal do software Softcom Slim. Foram cadastrados também todos os dados relativos à aplicação do Card Sorting em 10 participantes da pesquisa. Um dos participantes foi desconsiderado desta análise devido o resultado de seu Card Sorting ser considerado como um Outlier, e o seu uso poderia influenciar no resultado final da pesquisa criando um resultado infiel.

O primeiro resultado obtido (Figura 3) apresenta o agrupamento de todas as funções da interface principal do Softcom Slim em cinco grandes grupos de menu que representam o sistema avaliado. Estes cinco grandes grupos de menu foram assim designados: Financeiro; Sistema; Cadastros; Faturamento e; Relatórios (ordem em que os agrupamentos estão exibidos na Figura 3.

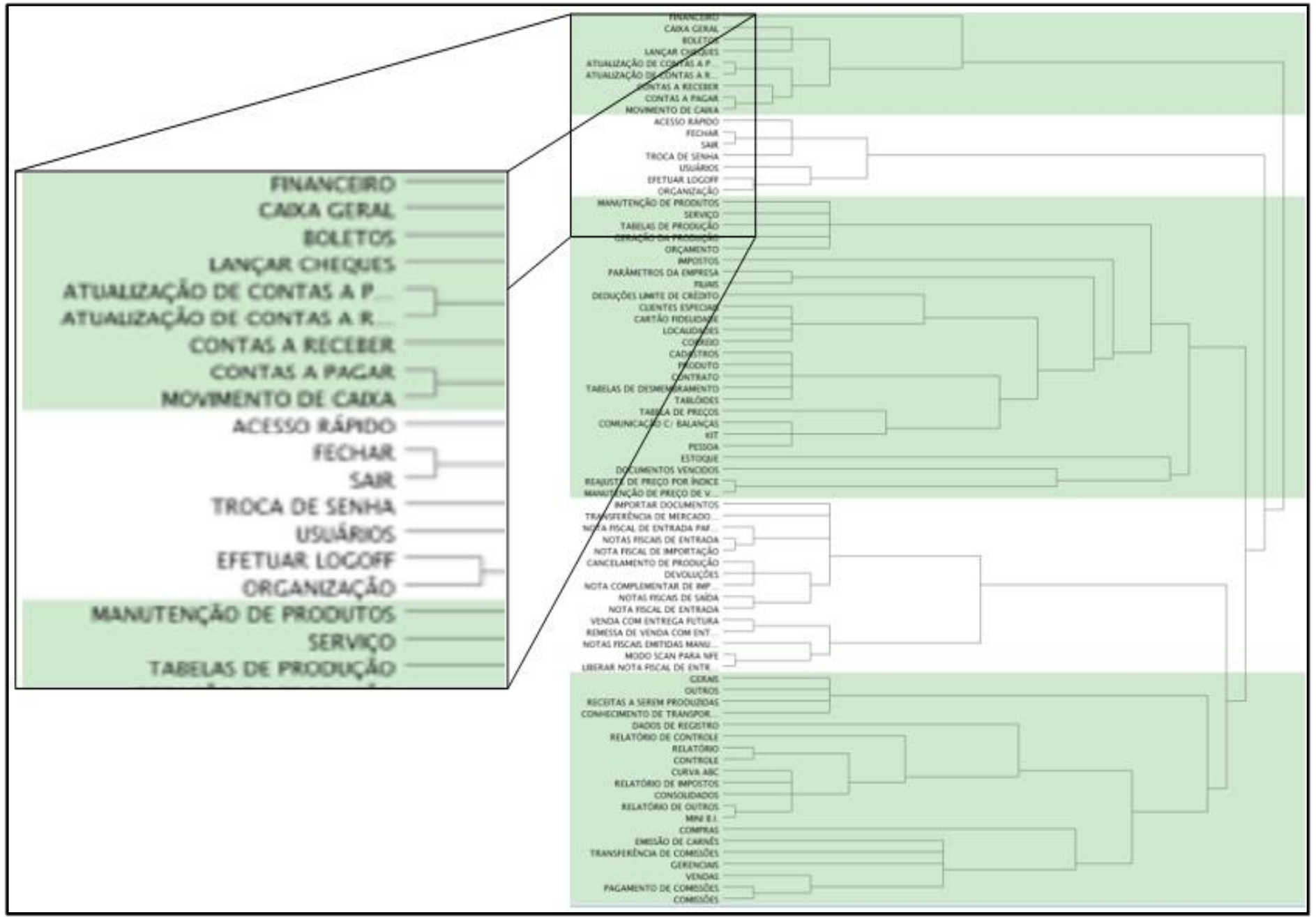

Figura 3 - Agrupamento dos itens do menu propondo nova taxonomia. 


\subsection{Protótipos desenvolvidos para avaliação}

Durante o processo de análise dos dados da pesquisa foi evidenciado um fator levantado em uma das questões do questionário de Pós-Teste.

A referida questão foi a seguinte: Considerando meios de solução de dúvidas, qual você considera ser mais eficaz? O participante deveria então selecionar uma dentre as opções disponíveis, que viria a solucionar o problema mencionado na questão. A opção que se destacou na escolha dos entrevistados, com um índice de 55\%, foi à opção de o sistema oferecer avisos suspensos, com dicas sobre o campo em dúvida.

A intenção com esta implementação seria a de o usuário ao localizar um campo no sistema ao qual lhe surja uma dúvida sobre o seu significado ou influência deste, possa pressionar a tecla F1, e o sistema proporcionará na forma de um aviso em janela ou canvas, o conceito de uso daquele campo, oferecendo desta forma uma explicação para quê serve o mesmo e consequentemente o que este influência ou pode exercer no restante do processo/sistema.

É demonstrado na Figura 4, em forma de protótipo de interface, como poderia ser a implementação desta solução escolhida.

Para a elaboração da interface do protótipo principal, foi levada em consideração toda a análise dos dados da pesquisa desenvolvida. Desta forma foi possível definir um padrão de interface que determina, baseado nos resultados coletados pela técnica de CardSorting e compilado pelo WebSort, uma nova taxonomia que se adéqua ao modelo mental dos usuários entrevistados.

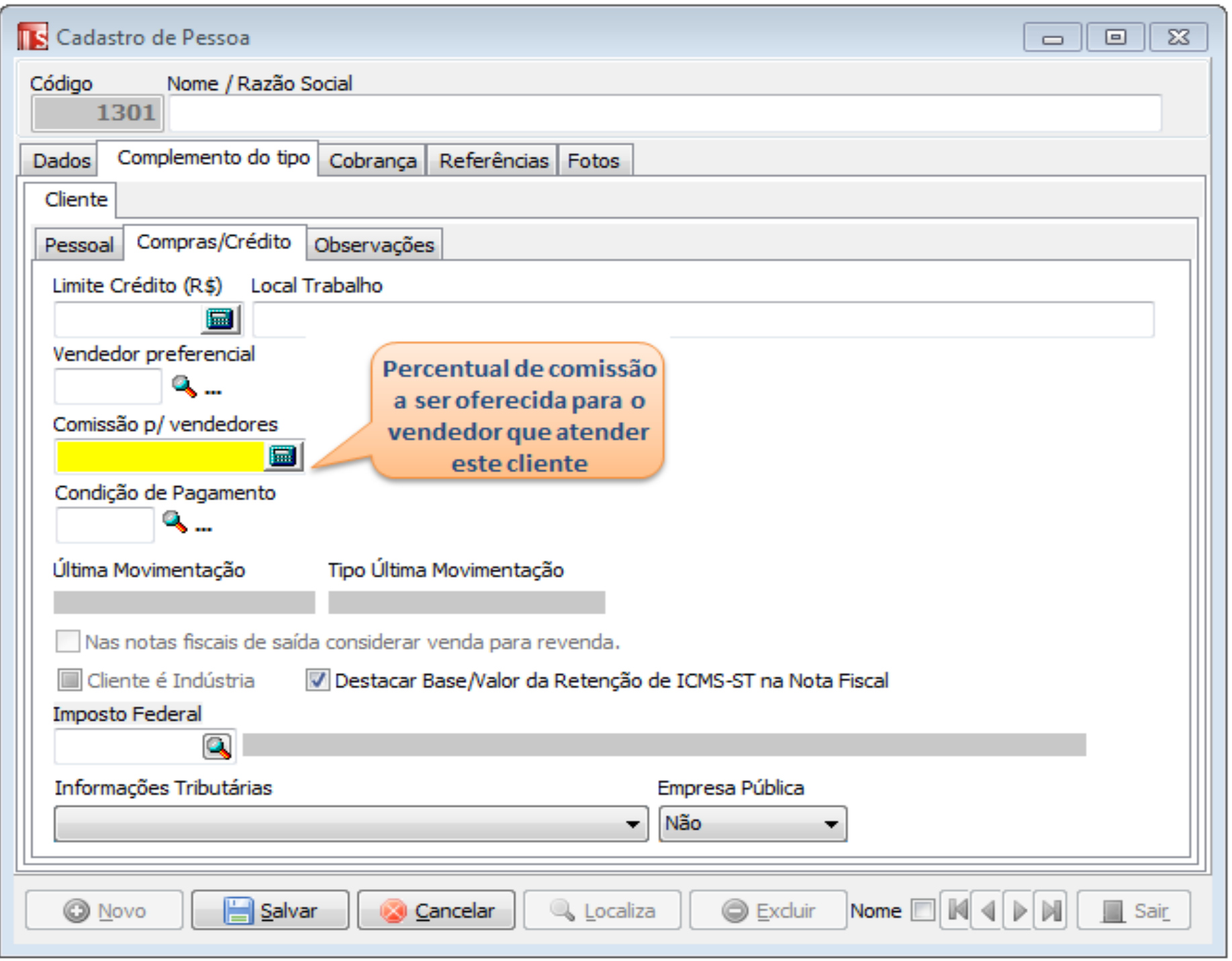

Figura 4 - Protótipo da solução escolhida para dúvidas em campos do sistema 
Para a construção do Wireframe não funcional da nova interface principal do software Softcom Slim, com a nova taxonomia proposta, utilizou-se o software Pencil. Este protótipo pode ser visto na Figura 5.

As opções contidas em cada menu, foram ordenadas de forma alfabética crescente. Também foram mantidas as opções dos ícones atalhos do teclado, que representam funções dentro do sistema atual. Como inovação, foi disponibilizado além da nova taxonomia, um campo de pesquisa para localização de rotinas que o usuário pretenda usar, mas não sabe onde se encontra. Este quesito obteve uma aceitação de $91 \%$ dos entrevistados.

\section{Conclusões}

Este estudo demonstrou algumas vantagens de se efetuar uma avaliação de usabilidade de um sistema já operando no mercado, e dentre todas que poderiam ser citadas a principal é a do conhecimento prévio do sistema pelos participantes da pesquisa. Por possuírem essa experiência de uso do sistema, tal conhecimento auxiliou na identificação de possíveis pontos falhos do mesmo, informação que muitas vezes vem seguida de sugestões e dicas de como resolver tais pontos falhos, auxiliando na melhoria do sistema como um todo.

Em contra partida, existe uma desvantagem nesse modelo de pesquisa, devido baixa aceitação da mesma pelos usuários. $\mathrm{O}$ principal argumento utilizado para a não participação da pesquisa é o fator tempo, por exemplo, quando um dos clientes ao ser convidado a participar da pesquisa respondeu "Como que vou destinar cerca de 40 minutos de um funcionário meu para participar da pesquisa? são 40 min que eu estou pagando e ele não estará faturando para mim". Ou ainda com relação ao fator tempo, principalmente em locais onde o estabelecimento que usa o software é pequeno, possui poucas pessoas para atender, e o fluxo de atenção aos clientes é alto.

Ficou evidenciado ainda que os usuários do sistema Softcom Slim, em sua maioria gostam de utilizar o sistema e o consideram ser de fácil uso, desta forma é bem aceito e conceituado pelos usuários. $\mathrm{O}$ sistema consegue demonstrar ao usuário uma interface que de fato ele utilize, mesmo que neste último item seja necessária atenção especial devido algumas

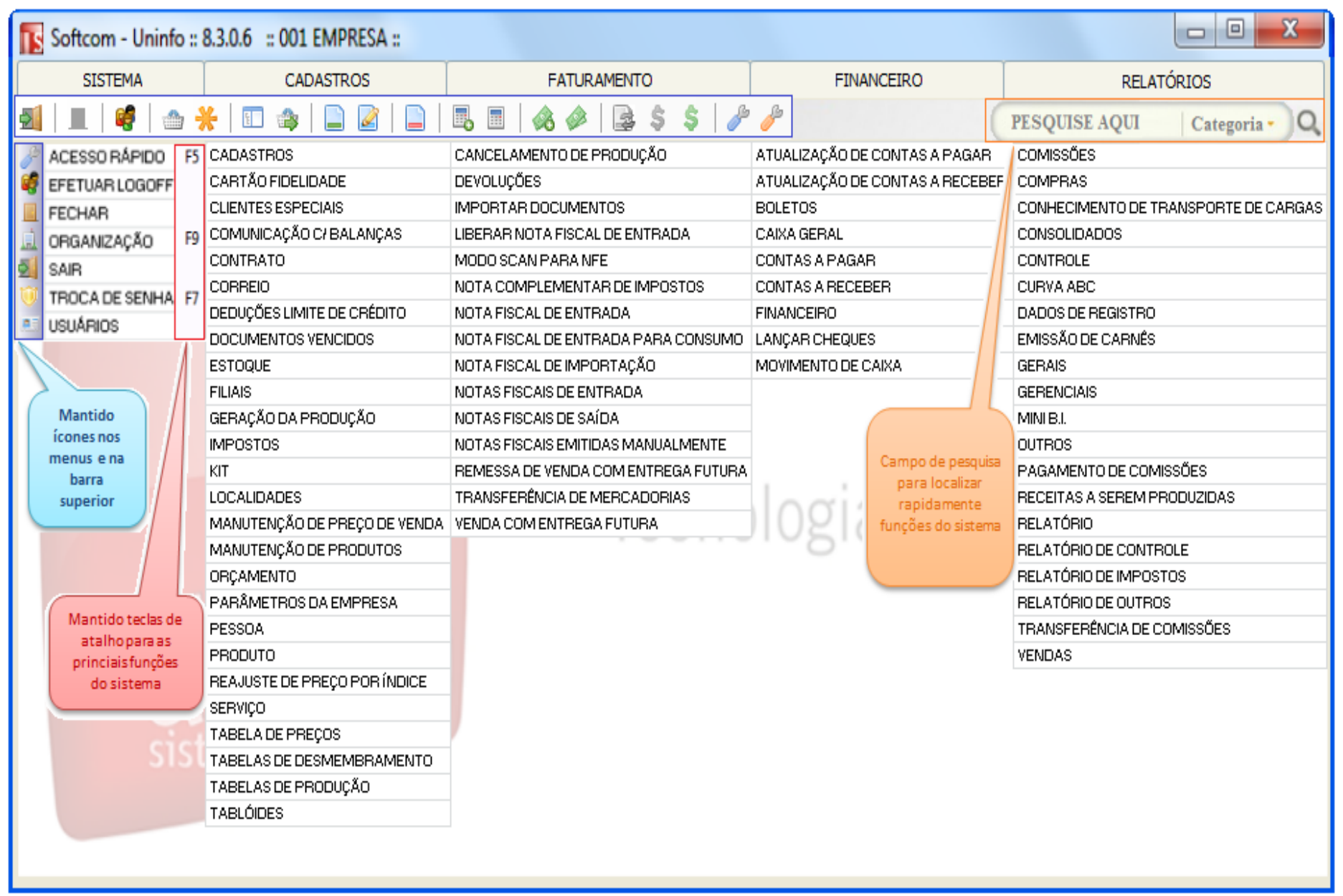

Figura 5 - Protótipo principal com a nova taxonomia proposta 
constatações feitas pelos usuários com relação à quantidade de informação que lhes aparece em cada tela. Este ponto é justificado pelo presente estudo, o qual demonstrou que apenas $45 \%$ dos entrevistados consideram ser fácil o uso dos menus do software avaliado. Porém cerca de $73 \%$ dos participantes conseguiram realizar as tarefas solicitadas com sucesso total ou parcial durante a avaliação do menu da interface principal do programa, demonstrando que a mesma é satisfatória e usual.

Por fim considerou-se que a avaliação da interface do programa Softcom Slim alcançou seu objetivo, pois foi possível medir a satisfação dos usuários quanto ao uso do sistema. Além de a pesquisa responder em sua totalidade as questões que levaram a sua execução, foi possível identificar alguns fatores novos que agregam peso nos resultados da pesquisa e que caso sejam implementados em novas versões do programa, possam aumentar ainda mais a satisfação do uso do mesmo.

\section{Agradecimentos}

Primeiramente agradeço a força criadora universal que é DEUS, sem ele isso nunca seria possível.

Agradeço o apoio de minha esposa e meu filho, família que sempre esteve ao meu lado em todas as fases (boas e não tão boas) deste estudo.

A empresa Uninfo Sistemas que permitiu o desenvolvimento da presente pesquisa, bem como a todos os seus clientes que colaboraram com o desenvolvimento desta.

A Universidade do Oeste de Santa Catarina - UNOESC campus Chapecó, que com seu corpo docente sempre me ensinaram a lutar e a buscar ultrapassar todo e qualquer limite imposto, transformando-o em potencial criador. Aqui aproveito para fazer um agradecimento especial ao meu orientador Jean Carlos Hennrichs, que acreditou no meu potencial e investiu sua dedicação e tempo para expandir e disseminar o assunto exposto.

\section{USABILITY EVALUATION OF THE INTERFACE OF COMPUTER ENTERPRISE RESOURCE PLANNING (ERP)}

ABSTRACT: This study aims to present some techniques and tools HCI (Human-Computer Interface) to help identify usability problems and possible solutions for these inconsistencies in an existing ERP system (Enterprise Resource Planning) and in use commercially. The fieldwork consisted of the application of the technique of Card Sorting, into actual customers of the company Uninfo Sistemas Chapecó-SC, to evaluate the taxonomy of the main interface of ERP Softcom Slim. From the results collected created a static prototype with the new taxonomy proposed, and finally, the evaluation of this new taxonomy by means of runtime, number of mouse clicks and route traveled. The choice of conducting research on a system already in use commercially showed advantages and disadvantages. The greatest advantage identified was the prior user knowledge of the system, because such knowledge helps to identify weak points of the taxonomy of the evaluated system. In contrast, the biggest drawback was the low acceptance of participation of clients who use the software in question, in this case being the time factor as the main reason for the lack of availability of the user to take the poll. Completed the survey and the proposed study came to the conclusion that the taxonomy of ERP software interface Softcom Slim would need some tweaking to make it more responsive, efficient and effective.

Keywords: Human-computer interface. Card Sorting. Wireframe. Interface usability. Ideal time for KLM.

\section{Referências}

[1] NBR ISO/IEC 9126-1. Engenharia de software - Qualidade de produto, Parte 1: Modelo de qualidade. 2003.

[2] NBR ISO/IEC 12207. Tecnologia da informação - Processos do ciclo de vida do software. 1998.

[3] NBR 9241-11. Requisitos Ergonômicos para Trabalho de Escritórios com Computadores, Parte 11: Orientações sobre Usabilidade. 2002.

[4] PRESSMAN, ROGER S. Engenharia de software. Tradução: Rosângela Ap. D. Penteado. 6. ed. Porto Alegre: AMGH, 2010. 720 p.

[5] CYBIS, WALTER et al. Ergonomia e usabilidade: Conhecimentos, Métodos e Aplicações. 2. ed. São Paulo: Novatec, 2007. 422 p.

[6] FARIA, MAURICIO MARQUES DE. Card sorting: noções sobre a técnica para teste e desenvolvimento de categorizações e vocabulários. Campinas: Revista Digital De Biblioteconomia E Ciência Da Informação, v. 7, n. 2, jan. 2010. Disponível em: <http://polaris.bc.unicamp.br/seer/ojs/index.php/ rbci/article/view/436/297>. Acesso em: 22 out. 2012.

[7] BROWN, DANIEL M. Communicating Design - Developing web Site Documentation for Design and Planning. Berkeley: New Riders, 2007.

[8] REIS, GUILERMO ALMEIDA DOS. Centrando a Arquitetura de Informação no usuário. São Paulo: USP, 2007.250p. Disponível em: <http://www.guilhermo.com/mestrado/Guilhermo_Reis-Centrando_a_Arquitetura _de_Informacao_no_usuario.pdf>. Acesso em: 03 out 2012.

[9] AMSTEL, FREDERICK VAN. Quanto mais simples o Wireframe, melhor, 2005. Disponível em: <http://www.usabilidoido.com.br/quanto_mais_simples_o_ wireframe_melhor.html>. Acesso em: 31 out. 2012.

[10] NIELSEN, J. Usability Engineering. Academic Press, Cambridge, MA, 1993. $362 \mathrm{p}$.

[11] BARANAUSKAS, M. C. C.; ROCHA, H. V. Design e Avaliação de Interface Homem-Computador. São Paulo: UME-USP, 2000.

[12] KIERAS, DAVID. Using the keystroke-level model to estimate execution times. University of Michigan, 1993. Disponivel em: <http://www.pitt.edu/ cmlewis/KSM.pdf>. Acesso em: 23 out. 2013.

[13] PRATI, RONALDO. Outliers Detecção de Anomalias: Aula Data Mining. Disponível em: <http://professor.ufabc.edu.br/ ronaldo.prati/DataMining/ Outliers.pdf>. Acesso em: 27 out. 2013. 